\title{
AUDIÊNCIA DE CUSTÓdIA: UMA VIA DE SOLUÇÃO FRENTE AO ATUAL COLAPSO DO SISTEMA PENITENCIÁRIO BRASILEIRO?
}

Custody hearing: a solution to the current collapse of the Brazilian penitentiary system?

\section{Nina Araújo Melo Leal ${ }^{1}$}

RESUMO: as audiências de custódia são um instrumento processual penal implantado há pouco tempo em nosso ordenamento jurídico, em que pese sua previsão em tratados e convenções internacionais aos quais o Brasil livremente aderiu há mais de vinte anos. Tendo em vista ter sido instituída em grave contexto de crise, é necessário investigar a real possibilidade de a audiência de custódia ser um instrumento de transformação dos procedimentos relacionados às prisões e, sobretudo, suficiente para diminuir sensivelmente o encarceramento de presos provisórios no país. Além disso, é preciso criar condições para que o novel instituto seja aperfeiçoado, bem como difundido para todas as comarcas e regiões do país. Nesse sentido, o presente trabalho objetiva investigar o alcance do instituto processual frente a atual crise no sistema penitenciário nacional.

PALAVRAS-CHAVE: Audiência de custódia; Prisões provisórias; Sistema penitenciário.

ABSTRACT: Custody hearings are a criminal procedural instrument recently established in our legal system, despite their prediction in international treaties and conventions to which Brazil has freely acceded for more than twenty years. In view of having been set up in a serious crisis, it is necessary to investigate the real possibility that the custody hearing will be a tool for transforming the procedures related to prisons and, above all, sufficient to significantly reduce the incarceration of interim prisoners in the country. In addition, it is necessary to create conditions for the institute to be perfected, as well as diffused for all regions and regions of the country. In this sense, the present work aims to investigate the scope of the procedural institute in the face of the current crisis in the national penitentiary system.

KEYWORDS: Custody hearing; Temporary prisions; Penitentiary system.

\footnotetext{
1 Advogada. Bacharel em Direito (Instituto Camillo Filho). Pós-graduanda em Direito Público pela Universidade Estadual do Piauí. Membro da Comissão de Educação Jurídica da OAB - PI.
} 


\section{INTRODUÇÃO}

É inegável a grave crise instaurada no Sistema Penitenciário Nacional, com a superlotação de penitenciárias e casas de custódia, péssimas condições de saúde e higiene no interior das celas e descaso do Estado na prestação dos direitos mínimos da pessoa presa. Tal problemática se agrava sobremaneira com a morosidade desproporcional dos processos criminais em trâmite no âmbito do Poder Judiciário, fazendo com que mais de um terço da população encarcerada não esteja definitivamente julgada.

Tal desproporção patente no número de presos provisórios no Brasil, aliado a outros fatores, tem culminado em rebeliões de grandes proporções no sistema penitenciário, bem como ocorrência de mortes diárias no interior do sistema prisional, instaurando-se um verdadeiro colapso no Sistema Penitenciário Nacional.

Os fatores processuais penais, econômicos e sociais que ensejam as referidas rebeliões já constam de diagnósticos realizados ao longo de anos, sendo correntes em debates entre o Poder Judiciário, as Secretarias de Segurança Pública e/ou de Justiça e as Defensorias Públicas, já documentados pela mídia e pelos estudiosos do tema.

Nesse contexto, a implantação das audiências de custódia (ou audiências de apresentação) foi colocada como proposta de solução para diminuir o grande índice de encarceramento de presos provisórios, pois, na sistemática anterior assinalada no artigo 310 do Código de Processo Penal, o juiz competente decidia sobre a situação do preso em flagrante apenas com a análise dos autos referentes ao procedimento, sem qualquer contato direto com a pessoa presa. Ao revés, na sistemática da audiência de custódia, como se verá, o julgador tem a oportunidade de ouvir e ser ouvido pela pessoa presa em flagrante, podendo tomar sua decisão a respeito da conversão (ou não) em alguma das formas de prisão cautelar, ou medidas cautelares diversas da prisão, com mais propriedade e convicção.

Este trabalho - com as limitações inerentes a um estudo de caráter preliminar - tem o escopo, considerando o contexto posto, de analisar em que medida as audiências de custódia são instrumentos hábeis para se alcançar diminuição do encarceramento em massa de presos provisórios no Brasil. Para investigar a referida questão, faz-se necessário entender brevemente a origem do instituto processual, sua regulamentação no Brasil e os fatores que podem contribuir (ou não) para sua plena efetividade no que tange à solução do problema apresentado.

\section{AS ORIGENS DA AUDIÊNCIA DE CUSTÓDIA NO ESTADO BRASILEIRO}


A realização de audiências de custódia no Brasil só foi possível após o percurso de um longo caminho, que se iniciou com a previsão da garantia de audiência de custódia em tratados e convenções internacionais, passando por projetos de lei e de emendas a constituição, que jamais tiveram suas tramitações finalizadas. Mais recentemente, a regulamentação se deu por meio de provimentos de tribunais específicos e, uniformizando o procedimento, regulamentação por parte do Conselho Nacional de Justiça, através de Resolução.

Essa longa marcha de implantação revela a dificuldade enfrentada para a efetiva execução dessa garantia fundamental, que por décadas foi renegada ao ostracismo na legislação e doutrina pátrias. Vejamos, em apertada síntese, este percurso de efetiva aplicação das audiências de custódia.

O primeiro documento internacional ratificado pelo Brasil que previu a audiência de custódia foi o Pacto Internacional de Direitos Civis e Políticos, ratificado pelo Brasil por meio do Decreto $n^{\circ}$ 592, de 06 de julho de 1992. O segundo, de maior notoriedade e conhecimento em nosso país, foi a Convenção Americana de Direitos Humanos (o Pacto de São José da Costa Rica), ratificado pelo Brasil por meio do Decreto no 678, de 09 de julho de 1992. Não é demais lembrar, por oportuno, que este último documento possui status de norma supralegal em nosso ordenamento ${ }^{1}$.

Ora, a presença da garantia de audiência em uma Convenção Internacional recepcionada em nosso ordenamento com status de supralegalidade não seria razão suficiente para a implantação e ampla efetivação do instituto processual penal em tela em todo o território nacional? Por óbvio que sim. Conforme PAIVA (2017, p. 69):

[...] O Brasil aderiu aos termos da Convenção Americana há mais de vinte anos, o que, por si só, já seria o bastante para que a audiência de custódia fosse respeitada e observada no nosso país. Os direitos e as garantias previstas nos tratados internacionais de direitos humanos não podem ficar, sob pena de ineficácia e enfraquecimento do sistema internacional de proteção dos direitos humanos, condicionados à correspondência normativa no Direito interno de cada país $[. .$.

Todavia, em que pese esta cristalina previsão nos documentos internacionais aos quais livremente o Brasil aderiu e, sobretudo, a grave situação de calamidade do sistema prisional, a garantia individual da audiência de custódia passou longos anos na esteira do esquecimento (intencional, sabemos) de nossos legisladores e gestores públicos. Passado esse período, alguns

\footnotetext{
${ }^{1}$ Em sede de Recurso Extraordinário RE 466.343, o Supremo Tribunal Federal conferiu status de supralegalidade a normas previstas em tratados internacionais que versam sobre matérias de Direitos Humanos que não tenham ingressado no ordenamento pátrio com status de emenda à Constituição.
} 
projetos de lei e de emenda à constituição passaram a tratar da matéria, dos quais se destacam o PLS 554/2011 e as PECs 112/2011 e 89/2015. Por suas conturbadas tramitações e por ainda não contarem com textos em vias de conclusão, não é salutar a discussão de cada um desses projetos.

Suprindo esse vácuo legislativo, entraram em cena regulamentações isoladas de cada Tribunal que instituiu as audiências de custódia em sua rotina, através de provimentos. Logo após, uniformizando a matéria, o Conselho Nacional de Justiça editou a Resolução 213/2015, atual norma de regência das audiências de custódia. Com a edição da referida resolução o instituto processual passou a ser paulatinamente implantado nos tribunais de justiça de todos os estados da federação.

\section{O QUE É UMA AUDIÊNCIA DE CUSTÓDIA E QUAIS SUAS PRINCIPAIS FINALIDADES}

Por se tratar de instituto processual relativamente novo na doutrina nacional e com alcance limitado mesmo no âmbito de advogados e outros operadores do Direito, faz-se necessário explicitar o que é uma audiência de custódia (ou de apresentação). Melhor síntese sobre o instituto é a de PAIVA (2017, p. 41):

O conceito de custódia se relaciona com o ato de guardar, de proteger. A audiência de custódia consiste, portanto, na condução do preso, sem demora, à presença de uma autoridade judicial que deverá, a partir do prévio contraditório estabelecido entre o Ministério Público e a defesa, exercer um controle imediato da legalidade e da necessidade da prisão, assim como apreciar questões relativas à pessoa do conduzido, notadamente a presença de maus tratos ou tortura $[\ldots]$

Nesse sentido, o preso em flagrante ou mesmo aquele que foi preso em decorrência de cumprimento de mandados de prisão cautelar ou definitiva (art. 13 da Resolução 213 do CNJ) deve ser apresentado, sem demora, a uma autoridade judicial. Nesta audiência estarão presentes também o Ministério Público e a defesa (Defensoria Pública ou Advogado particular), de forma que a análise, pelo julgador, da legalidade e necessidade da prisão, será precedida de maior discussão sobre suas circunstâncias, bem como é possível que o juiz colha mais elementos de convicção ao estar frente à frente com a pessoa presa, oportunidade que não lhe era franqueada na sistemática anterior, isto é, na previsão, constante do artigo 310 do CPP, de mera análise de um relato escrito em papel. Além disso, a audiência de custódia é instrumento instituído para que o juiz questione a pessoa presa sobre eventual ocorrência de maus tratos ou tortura durante sua condução ou em qualquer momento anterior à realização de sua oitiva. 
Não paira pela doutrina dúvida de que a oitiva do réu pelo juiz, antecedida dos devidos esclarecimentos sobre o escopo da audiência e os direitos da pessoa presa, é momento capaz de elucidar diversas dúvidas a respeito das circunstâncias da prisão e das condições ou características do próprio acusado, ampliando-se o rol de informações que o magistrado tem para subsidiar sua decisão, bem como oportunizando ao réu uma chance única de externar sua visão dos fatos e, com auxílio de defesa técnica, ampliar suas chances de não ser encarcerado cautelarmente. Em razão desses fatores, a doutrina aponta, acertadamente, o papel humanizador da audiência de custódia:

Quando se afirma que a audiência de custódia humaniza o processo penal, o que se pretende demonstrar é que retira os sujeitos do processo penal do lugar tranquilo dos burocratas anônimos e os coloca, juntos, diante da pessoa presa, a quem se deve assegurar o direito de ser ouvida, e não apenas o direito de ser lida. Sai de cena o sistema puramente cartorial, em que o juiz decidia sobre a liberdade da pessoa unicamente a partir do papel. Entra em cena a oralidade, um expediente ignorado e muito pouco utilizado no processo penal brasileiro (PAIVA, 2017, p. 139).

Outra não é a dicção da doutrina de LOPES JR. e MORAIS DA ROSA (2015, p.22):

[...] Eis um ponto crucial da audiência de custódia: o contato pessoal do juiz com o detido. Uma medida fundamental em que, ao mesmo tempo, humanizase o ritual judiciário e criam-se as condições de possibilidade de uma análise acerca do periculum libertatis, bem como da suficiência e adequação das medidas cautelares diversas da prisão do artigo 319 do CPP.

Estes são os contornos mínimos do instrumento processual em estudo. Em síntese, a audiência de custódia visa decidir sobre a prisão e sua necessidade, bem como perquirir sobre eventual violência contra o acusado, não se destinando, em regra, a analisar fatores do suposto crime cometido ou circunstâncias de sua consumação, avaliações que ocorrerão nos momentos processuais adequados.

Aspecto de extrema relevância, igualmente, é a função de combate à tortura e outras formas de violência, diante dos recorrentes relatos de violência policial ou descumprimento de normas de Direitos Humanos nas ocasiões de flagrante e/ou na condução de pessoas presas. Tanto é assim que um dos objetivos das audiências de custódia consiste em:

[...] Averiguar a ocorrência de algum tipo de violência porventura praticada contra a pessoa apresentada, em particular, tortura ou maus-tratos, desde a efetivação de sua prisão cautelar por parte das autoridades públicas encarregadas do ato, até o momento de sua apresentação em audiência de custódia. (ANDRADE; ALFLEN, 2016, p. 19) 
Sendo assim, pode-se resumir o papel das audiências de custódia ou apresentação em três frentes: a investigação e discussão sobre a legalidade e a necessidade da prisão em análise; o combate da violência e tortura contra a pessoa detida; e a busca por uma maior humanização do processo penal, com maior oportunidade de oitiva da pessoa presa, respeitando-se diversas garantias individuais inerentes ao cárcere.

\section{O PAPEL DAS AUDIÊNCIAS DE CUSTÓDIA NO CONTROLE DO ENCARCERAMENTO PROVISÓRIO NO BRASIL}

Conforme já antecipado, a doutrina coloca como escopo central das audiências de custódia a diminuição de prisões ilegais ou desnecessárias, o que seria possível por que o julgador, em contato direto com a pessoa presa, teria maiores condições de conceder sua liberdade e aplicar medidas cautelares diversas da prisão, ou, eventualmente, se valer de prisões domiciliares ou encaminhamento da pessoa detida a serviços de atendimento social ou assistencial.

$\mathrm{Na}$ mesma perspectiva, relevante doutrina aponta até mesmo maior humanização do preso quando se realiza audiência de custódia, ao invés de mera análise do auto de prisão em flagrante. Se percebe também a ampliação do contraditório na esfera dos procedimentos relacionados com a prisão, favorecendo a efetivação de diversas garantias individuais, ampliandose, em alguma margem, a dignidade humana do preso.

Todavia, a discussão do papel desse instrumento processual penal não pode ocorrer apenas no plano teórico, no qual a mera possibilidade do alcance de seus objetivos se revela em uma verdadeira tábua de salvação para a crise pela qual passa o sistema penal como um todo. Quando se trata de um instituto como a audiência de custódia, só a análise da rotina das varas e tribunais brasileiros é capaz de revelar a contribuição do instrumento para o alcance dos anseios ensejadores de sua implantação neste Estado.

Ainda que de forma prematura, os números colhidos e disponibilizados pelo $\mathrm{CNJ}^{1}$ podem revelar um panorama dos resultados do primeiro ano de realização de audiências de custódia no Brasil. Conforme números obtidos da realização das audiências até meados do mês de dezembro de 2016, foram realizadas 174.242 audiências de custódia no Brasil, das quais 80.508, isto é, $46,20 \%$, resultaram em liberdade. Ao contrário, 93.734, isto é, 53,80\%, resultaram em prisão

\footnotetext{
${ }^{1}$ Tais números se referem a todas as audiências de custódia realizadas até meados do mês de dezembro de 2016, catalogadas pelo CNJ. Dados disponíveis em http://www.cnj.jus.br/sistema-carcerario-e-execucao-penal/audienciade-custodia/mapa-de-implantacao-da-audiencia-de-custodia-no-brasil
} 
preventiva. Do montante total, apenas 19.626 (o que representa cerca de 11,26\%) resultaram em algum encaminhamento social ou assistencial.

Dessa forma, pode-se perceber que a quantidade de prisões preventivas é muito superior aos casos de liberdade, o que está em sentido diametralmente oposto ao postulado de que a prisão cautelar deve ser excepcional, e não a regra geral.

A doutrina aponta, frente a isso, o grave risco de transformação da audiência de custódia em mero expediente burocrático ou obrigação protocolar, como alertam ANDRADE e ALFLEN (2015, p. 69):

A audiência de custódia pode significar uma revolução no sistema de Justiça Criminal, uma ruptura com um passado de invisibilidade do preso, mas pode, também, se não conduzida com responsabilidade, ser apenas mais um expediente, em meio a tantos outros, a confirmar a célebre frase do escritor italiano Giuseppe Tomasi di Lampedura: "Tudo deve mudar para que tudo fique como está".

Diversos são os fatores que podem contribuir para a permanência da cultura do encarceramento, apesar do maior diálogo processual proporcionado pela audiência de custódia, entre os quais estão a inserção recente do instituto das audiências de custódia, o qual ainda não teve o amadurecimento prático que o tempo proporciona, bem como não teve sua efetivação concreta no interior dos estados da federação; o desconhecimento ou descrença dos julgadores em relação às medidas cautelares diversas da prisão; e, sobretudo, a mentalidade inquisitória e fortemente punitivista que ainda paira sobre considerável parcela do Judiciário e de outras instituições inseridas no Sistema Penal.

\section{CONSIDERAÇÕES FINAIS}

Conforme demonstrado, a audiência de custódia é instrumento processual fundamental para o Estado brasileiro, que se alinha aos mais caros direitos fundamentais da pessoa humana e traz notórios benefícios ao Sistema Penal como um todo, favorecendo, inclusive, o seu aspecto civilizatório.

Após ampla discussão da matéria e o enfrentamento de diversas barreiras e oposições, a implantação da audiência de custódia em nosso ordenamento é conquista que deve ser amplamente festejada pela doutrina nacional, com o empreendimento de todos os esforços para a sua continuidade e aperfeiçoamento. 
Outros pontos devem ainda ser ainda considerados para a consolidação do instituto, tais como melhorias nas estruturas físicas onde se realizam as audiências, ampliação dos meios de transporte dos presos, formação e aperfeiçoamento de todos os sujeitos envolvidos, entre outros. Ao mesmo tempo, o olhar sobre o papel das audiências de custódia deve ser revestido de cautela, pois, se não houver uma mudança em outros paradigmas inseridos na persecução penal, a implantação desse instituto está fadada a ser tornar cumprimento de formalidades protocolares, sem qualquer revolução nos resultados da medida.

Assim, por todo o exposto, adotando-se uma posição de homenagem ao novel instrumento, não se pode tirar os pés do chão, analisando e questionando quais as mudanças que efetivamente precisam ocorrer para o alcance dos objetivos almejados, proporcionando um resultado satisfatório.

\section{REFERÊNCIAS}

ANDRADE, Mauro Fonseca; ALFLEN, Pablo Rodrigo (orgs.). Audiência de custódia: comentários à Resolução 213 do Conselho Nacional de Justiça. 1. ed. Porto Alegre: Livraria do Advogado, 2016.

LOPES JR., Aury; MORAIS DA ROSA, Alexandre. Processo penal no limite. 1. ed. Florianópolis: Empório do Direito, 2015.

OLIVEIRA, Eugênio Pacelli de. Curso de Processo Penal. 20. ed. São Paulo: Atlas, 2016.

PAIVA, Caio. Audiência de custódia e o processo penal brasileiro. 2. ed. Florianópolis: Empório do Direito.

http://www.cnj.jus.br/sistema-carcerario-e-execucao-penal/audiencia-decustodia/mapa-da-implantacao-da-audiencia-de-custodia-no-brasil (último acesso em 12 de dezembro de 2016). 